Article

\title{
Fabrication of Polydimethysiloxane (PDMS) Dense Layer on Polyetherimide (PEI) Hollow Fiber Support for the Efficient $\mathrm{CO}_{2} / \mathrm{N}_{2}$ Separation Membranes
}

\author{
Guoqiang Li ${ }^{1}$, Katarzyna Knozowska ${ }^{1}$, Joanna Kujawa ${ }^{1} \mathbb{D}$, Andrius Tonkonogovas ${ }^{2} \mathbb{D}$, Arūnas Stankevičius ${ }^{2}$ \\ and Wojciech Kujawski $1,3, *$ (i) \\ 1 Faculty of Chemistry, Nicolaus Copernicus University in Torun, 7, Gagarina Street, 87-100 Torun, Poland; \\ grantli@doktorant.umk.pl (G.L.); katkno@doktorant.umk.pl (K.K.); joanna.kujawa@umk.pl (J.K.) \\ 2 Lithuanian Energy Institute, 3, Breslaujos Street, LT-44403 Kaunas, Lithuania; \\ Andrius.Tonkonogovas@lei.lt (A.T.); Arunas.Stankevicius@lei.lt (A.S.) \\ 3 National Research Nuclear University MEPhI, 31, Kashira Hwy, 115409 Moscow, Russia \\ * Correspondence: kujawski@chem.umk.pl; Tel.: +48-566-114-517
}

check for

updates

Citation: Li, G.; Knozowska, K.; Kujawa, J.; Tonkonogovas, A.; Stankevičius, A.; Kujawski, W. Fabrication of Polydimethysiloxane (PDMS) Dense Layer on

Polyetherimide (PEI) Hollow Fiber Support for the Efficient $\mathrm{CO}_{2} / \mathrm{N}_{2}$ Separation Membranes. Polymers 2021, 13, 756. https://doi.org/ $10.3390 /$ polym 13050756

Academic Editor: Damien Quémener

Received: 13 February 2021

Accepted: 25 February 2021

Published: 28 February 2021

Publisher's Note: MDPI stays neutral with regard to jurisdictional claims in published maps and institutional affiliations.

Copyright: (c) 2021 by the authors. Licensee MDPI, Basel, Switzerland. This article is an open access article distributed under the terms and conditions of the Creative Commons Attribution (CC BY) license (https:// creativecommons.org/licenses/by/ $4.0 /)$.

\begin{abstract}
The development of thin layer on hollow-fiber substrate has drawn great attention in the gas-separation process. In this work, polydimethysiloxane (PDMS)/polyetherimide (PEI) hollowfiber membranes were prepared by using the dip-coating method. The prepared membranes were characterized by Scanning Electron Microscope (SEM), energy-dispersive X-ray spectroscopy (EDX), and gas permeance measurements. The concentration of PDMS solution and coating time revealed an important influence on the gas permeance and the thickness of the PDMS layer. It was confirmed from the SEM and EDX results that the PDMS layer's thickness and the atomic content of silicon in the selective layer increased with the growth in coating time and the concentration of PDMS solution. The composite hollow-fiber membrane prepared from $15 \mathrm{wt} \%$ PDMS solution at $10 \mathrm{~min}$ coating time showed the best gas-separation performance with $\mathrm{CO}_{2}$ permeance of $51 \mathrm{GPU}$ and $\mathrm{CO}_{2} / \mathrm{N}_{2}$ ideal selectivity of 21 .
\end{abstract}

Keywords: polyetherimide (PEI) hollow-fiber support; thin film composite membranes; dip-coating conditions; polydimethysiloxane (PDMS) dense layer; gas separation

\section{Introduction}

$\mathrm{CO}_{2}$ emission is inevitable owing to the growth of fossil fuel power plants and energyintensive industries [1]. The excess of $\mathrm{CO}_{2}$ emission has significantly affected the global warming, sea level rise, and climate changes. Therefore, the conversion, capture, and separation of $\mathrm{CO}_{2}$ are crucial to tackle the abovementioned environmental problems attracting a plenty of attention in science and engineering in 21st century [2-4]. Several conventional techniques like amine adsorption, Pressure Swing Adsorption (PSA), and cryogenic distillation are used for $\mathrm{CO}_{2}$ separation [5-7]. However, these processes are energy and cost intensive. Membrane process is an energy efficient technology for $\mathrm{CO}_{2}$ separation [8]. The characteristics of the membrane process, such as simple operation, small footprint, and low cost, make it more competitive than the conventional gas-separation processes [9].

Both flat sheet and hollow-fiber membranes can be applied for $\mathrm{CO}_{2}$ separation $[8,10,11]$ Comparing these two types of membrane configuration, it can be stated, that hollow fibers are easier to be scaled-up, owing to their high packing density and a self-supporting structure [8,12-14]. Polymer materials such as polysulfone (PSf) [15-17], polyetherimide (PEI) [18-21], polyimide (PI) [22,23], polyacrylonitrile (PAN) [24], and polyvinylidene fluoride (PVDF) [25] are commonly applied for the preparation of hollow fibers.

Membranes offering the high gas permeance are crucial to the gas-separation process at industrial scale. To obtain a membrane with high gas permeance and reasonable selectivity, 
either the highly permeable materials are used or the thickness of dense selective layer must be reduced. However, highly permeable materials show rather low selectivity, due to the trade-off relationship of polymeric membranes [26]. Therefore, the preparation of asymmetric composite membranes consisting of a thin dense layer and a porous substrate is a desirable method to improve the gas-separation performance of membranes [27].

The dip-coating technique [28-30] and interfacial polymerization (IP) [31-33] are generally applied for the preparation of asymmetric composite membranes. The formation parameters play important roles in the formation of composite membrane with high gasseparation performance. Madaeni et al. [28] prepared polydimethysiloxane (PDMS) coated polyethersulfone (PES) composite membranes for $\mathrm{CO}_{2}$ capture. They investigated the coating conditions such as coating temperature, PDMS concentration and the number of sequential coatings. A total of $5 \mathrm{wt} \%$ PDMS was reported as an optimal concentration for the dip-coating process. The increase of the coating layer number increased the PDMS layer thickness and selectivity, however, significantly decreased the gas permeance [28]. Li et al. [34] prepared PDMS/polyacrylonitrile (PAN) composite hollow-fiber membranes via the dip-coating method for $\mathrm{CO}_{2} / \mathrm{N}_{2}$ separation. It was found that the pre-wetting of PAN substrate could inhibit the intrusion of PDMS enabling the formation of defect-free selective layer [34]. Chen et al. [35] fabricated polyether block amide (Pebax)/PDMS/PAN composite hollow-fiber membranes via the dip-coating method and demonstrated that the prepared membranes could be used for flue gas treatment and hydrogen purification. PDMS was firstly coated on the PAN substrate to act as a gutter layer. The Pebax solution intrusion was minimized due to the PDMS gutter layer. Consequently, high gas permeance was obtained. The coating time and coating solution concentration are very important to the preparation of defect-free multi-layer hollow-fiber membranes [35]. Jo et al. [36] prepared inside coated thin film composite hollow-fiber membranes via interfacial polymerization. It was found that the concentrations of amine solution and acid chloride solution play crucial roles in determining the morphology and gas transport behavior of membranes. The high $\mathrm{CO}_{2} / \mathrm{CH}_{4}$ selectivity of the prepared membrane was attributed to the formation of ultrathin film and the properties of binary amino groups [36]. The aforementioned examples demonstrate the need for the creation of thin dense layer on the porous supports for gas separation. The conditions for the preparation of dense thin layer on porous supports are specifically addressed, since the optimization of the fabrication conditions is critically important to the formation of defect-free thin layer. These results from the literature are very close to our research work, since they present the gas-separation performance of PDMS or Pebax layer on various polymer supports.

In addition to the experimental investigation on the gas-separation behavior in the thin-film-composite hollow-fiber membranes, the theoretical and modeling studies are also applied for the study of mass transfer through hollow-fiber membranes in literature. Xiao et al. [37] applied a fractal model for the capillary flow through a single tortuous capillary with rough surfaces in fibrous porous media. Ghobadi et al. [38] conducted a 2D mass-transfer simulation model, using computational fluid dynamics (CFD) for separation of $\mathrm{CO}_{2}$ from a binary gas mixture of $\mathrm{CO}_{2} / \mathrm{CH}_{4}$ by means of polytetrafluoroethylene (PTFE) hollow-fiber membrane contactor.

PDMS and PEI are commercially available polymers. PDMS has been widely used in gas-separation process. The aim of this research was to prepare PDMS/PEI composite hollow fiber membranes via the dip-coating method for $\mathrm{CO}_{2} / \mathrm{N}_{2}$ separation. The influences of coating conditions such as the concentration of coating solution, coating time, curing temperature and the number of coating layers on the membrane structure, the gas permeance and ideal selectivity were systematically investigated. The optimization of coating conditions addressed in this study is one of the most outstanding research issues for the fabrication of defect-free thin dense layer on the porous support for gas separation. This experimental work is oriented to the practical application instead of theoretical and modeling studies even though they are also very important to the membrane-based gas-separation processes. 


\section{Experimental}

\subsection{Materials}

Polyetherimide (PEI, Ultem 1000) pellets were kindly provided by Membrain (Stráž pod Ralskem, Czech Republic). N-methyl-2-pyrrolidone (NMP, 99.5\%) was bought from Linegal Chemicals Sp. z o.o. (Warsaw, Poland). Methanol and n-hexane were purchased from Alchem Grupa Sp. z o.o. (Torun, Poland). Pure $\mathrm{CO}_{2}(99.999 \%)$ and $\mathrm{N}_{2}(99.999 \%)$ gases were purchased from Air Products Sp. z o.o. (Siewierz, Poland). The fast solidified epoxy resin Araldite 2000 and 3M EPX Quadro Mixing Nozzles were delivered by Farnell (Warsaw, Poland). Elastosil LR 6240A (containing platinum catalyst) and Elastosil LR 6240B (containing crosslinker) were provided by Wacker Chemie AG Polska Sp. z o.o. (Warsaw, Poland).

\subsection{Fabrication of PEI Hollow Fibers}

Dope solution with PEI concentration $20 \mathrm{wt} \%$ was prepared by dissolving PEI pellets in NMP in a round bottom flask under refluxing condition at $60^{\circ} \mathrm{C}$ for $24 \mathrm{~h}$. Prior to dissolving PEI pellets in NMP, they were dried in oven at $100{ }^{\circ} \mathrm{C}$ to remove the traces of moisture. The prepared dope solution was transferred into a laboratory screw cap bottle and left for $24 \mathrm{~h}$ for degassing. The PEI hollow fibers were prepared via the dry-jet wet spinning process by using a laboratory-built spinning system [8,39]. The spinning conditions are shown in Table 1 . In the spinning process, gear pump was used to deliver the dope solution at a specific extrusion rate from the stainless-steel reservoir to a spinneret. The bore fluid was delivered into the spinneret simultaneously by using a syringe pump. The as-spun hollow fibers went through an air gap and free fall into a coagulation bath containing distilled water, at room temperature. The prepared hollow fibers were cut and soaked in another water bath for 2 days, to remove the remaining NMP solvent. The hollow fibers from water bath were immersed into methanol for $12 \mathrm{~h}$. Afterwards, the methanol-wet hollow fibers were immersed into hexane for $12 \mathrm{~h}$. At last, hollow fibers were taken out from hexane and dried at room temperature, before further investigations. The physical properties of PEI hollow fibers have been fully investigated and presented in our previous work [39]; the basic parameters related to the diameters, wall thickness, skin layer thinness, and gas transport properties of hollow fibers are gathered in Table 2.

Table 1. Spinning parameters for polyetherimide (PEI) hollow-fiber fabrication.

\begin{tabular}{cc}
\hline Spinning Parameters & Spinning Conditions \\
\hline Spinneret dimensions, outer diameter $/$ inner & $4.8 / 2.1$ \\
diameter $(\mathrm{mm} / \mathrm{mm})$ & Distilled water \\
Bore fluid & $9-12$ \\
Bore fluid flow rate $(\mathrm{mL} / \mathrm{min})$ & $25 \pm 2$ \\
Bore fluid temperature $\left({ }^{\circ} \mathrm{C}\right)$ & 25 \\
Dry air gap length $(\mathrm{cm})$ & 7.6 \\
Dope extrusion rate $(\mathrm{mL} / \mathrm{min})$ & Free fall \\
Take up & Water \\
External coagulant & $25 \pm 2$ \\
Temperature of external coagulant $\left({ }^{\circ} \mathrm{C}\right)$ & $25 \pm 2$ \\
Temperature of spinneret $\left({ }^{\circ} \mathrm{C}\right)$ & 2
\end{tabular}

Table 2. Material and transport characteristics of the prepared hollow-fiber substrate [39].

\begin{tabular}{ccccccc}
\hline $\mathbf{d}_{\text {outer }}(\mu \mathrm{m})$ & $\mathbf{d}_{\text {inner }}(\mu \mathrm{m})$ & $\mathbf{l}_{\text {wall }}(\mu \mathrm{m})$ & Outer Skin $(\mu \mathrm{m})$ & Inner Skin $(\mu \mathrm{m})$ & $\mathbf{C O}_{\mathbf{2}}$ Permeance $(\mathrm{GPU})$ & $\mathrm{CO}_{\mathbf{2}} / \mathbf{N}_{\mathbf{2}}$ Selectivity \\
\hline $1446 \pm 100$ & $1053 \pm 81$ & $194 \pm 43$ & $2.40 \pm 0.90$ & $0.37 \pm 0.07$ & 6427 & 1.07 \\
\hline
\end{tabular}




\subsection{Dip-Coating Procedure}

The coating process was performed on the outer surface of membranes, by applying the following procedure. First of all, PDMS component A and B with mass ratio of 1:10 were dissolved in hexane, to prepare 1.5, 3, 5, 7, 10, 15, and $20 \mathrm{wt} \%$ PDMS-coating solution. The solution was prepared by stirring its components for $2 \mathrm{~h}$ at room temperature. The PEI hollow fibers were immersed into the PDMS solutions of various concentrations for $10 \mathrm{~min}$ at room temperature. To investigate the coating time effect, hollow fibers were immersed into $15 \mathrm{wt} \%$ PDMS solution for various coating time of $0.5,1,3,5,7,10$, and $15 \mathrm{~min}$ at room temperature. The PDMS/PEI membranes prepared from $15 \mathrm{wt} \%$ PDMS solution and 10 min coating time were cured at various temperatures of $25,50,80$, and $130{ }^{\circ} \mathrm{C}$ for $1 \mathrm{~h}$. Moreover, a sequential coating process was conducted by dip-coating hollow fibers into $15 \mathrm{wt} \%$ PDMS solution for $10 \mathrm{~min}$, several times, at room temperature, to investigate the effect of the number of PDMS layers. All the prepared PDMS/PEI composite hollow-fiber membranes were dried in air for at least $48 \mathrm{~h}$, to remove the solvent and to fully cure the PDMS.

\subsection{Characterization of PDMS/PEI Membranes}

The morphology of the fabricated PEI hollow fibers and PDMS/PEI composite membranes were characterized by using Scanning Electron Microscope (SEM)—LEO 1430 VP microscope (Leo Electron Microscopy Ltd., Cambridge, UK). The scanning was performed at an accelerating voltage of $30 \mathrm{keV}$. To analyze the cross section of hollow fibers, the samples were prepared by fracturing fibers frozen in liquid nitrogen. Prior to the analysis, samples were sputtered with a conductive layer (thickness in the range of 2-6 nm) of $\mathrm{Au} / \mathrm{Pd}(80 / 20)$ alloy. The energy-dispersive X-ray spectroscopy (EDX) analysis was conducted by using Phenom Prox/Pro/Pure, Generation 5 (Phenom-Word B. V., Eindhoven, The Netherlands). The PDMS layer thicknesses taken at the top and bottom parts of the prepared composite membranes were measured using SEM photos and ImageJ software (University of Wisconsin, Madison, WI, USA).

\subsection{Module Preparation and Gas Permeance Measurements}

To prepare the module, 2 hollow fibers with a length of $15-20 \mathrm{~cm}$ were assembled as a bundle. One hollow-fiber bundle was placed in a glass tube. Briefly, the single hollow-fiber bundle was placed in a glass tube. Both ends of the glass tube were sealed with a $5 \mathrm{~min}$ fast solidified epoxy resin (Araldite, Winterthur, Switzerland). Subsequently, one end of the glass tube was opened by using a scalpel before the complete solidification of epoxy resin. The details related to the module preparation are described elsewhere [39]. Pure $\mathrm{N}_{2}$ and $\mathrm{CO}_{2}$ were used for the single gas permeance tests. The trans-membrane pressure was set at 2 bar for all measurements, at room temperature, i.e., $25^{\circ} \mathrm{C}$. To ensure the accuracy of experiments, the gas permeance measurements were accomplished 3 times, in the stabilized conditions. A bubble flow meter was used to measure the gas flow rate. The permeances of gases expressed in GPU and the ideal selectivity expressed in the ratio of $\mathrm{CO}_{2}$ permeance to $\mathrm{N}_{2}$ permeance were used to estimate the gas-separation performance of PDMS/PEI composite hollow-fiber membranes. The permeances $(\mathrm{P} / \mathrm{d})$, of gases through the hollow-fiber module were calculated by using Equation (1):

$$
\frac{\mathrm{P}}{\mathrm{d}}=\frac{\mathrm{Q}}{\Delta \mathrm{pA}}=\frac{\mathrm{Q}}{2 \mathrm{n} \pi \mathrm{rl} \Delta \mathrm{p}}
$$

where $P$ is the permeability (Barrer), $d$ is the thickness of membrane selective layer $(\mathrm{cm})$, $\mathrm{Q}$ is the flux of gas permeation rate $\left(\mathrm{cm}^{3}(\mathrm{STP}) / \mathrm{s}\right), \Delta \mathrm{p}$ is the pressure difference across the membrane $(\mathrm{cmHg}), \mathrm{A}$ is the effective membrane area $\left(\mathrm{cm}^{2}\right), \mathrm{n}$ is the number of hollow fibers, $\mathrm{r}$ is the outer radius $(\mathrm{cm})$ of hollow fiber, and $\mathrm{P} / \mathrm{d}$ is the gas permeance expressed in GPU ( $\left.1 \mathrm{GPU}=10^{-6} \mathrm{~cm}^{3}(\mathrm{STP}) \mathrm{cm}^{-2} \mathrm{~s}^{-1} \mathrm{cmHg}^{-1}\right)$. 
The ideal selectivity, $\alpha$, is defined as the permeability coefficients or permeances ratio of two pure gases (Equation (2)):

$$
\alpha_{12}=\frac{(\mathrm{P} / \mathrm{d})_{1}}{(\mathrm{P} / \mathrm{d})_{2}}=\frac{\mathrm{P}_{1}}{\mathrm{P}_{2}}
$$

\section{Results and Discussion \\ 3.1. Membrane Morphology}

The structure and morphology of the cross-section of the uncoated PEI hollow fibers are shown in Figure 1. Figure 1a presents the overall cross-section of the prepared hollow fiber. The prepared hollow fibers possess finger-like macrovoids near lumen and shell sides, tear-like macrovoids underneath the finger-like macrovoids, microporous structure in the middle of hollow-fiber wall (Figure 1b), and relatively thin dense skin layer on the inner surface (Figure 1c) and outer surface (Figure 1d) of hollow fibers. The resulting membrane morphology is affected by the polymer-solvent interactions, solvent-coagulant interactions and the concentration and viscosity of the dope medium [40,41]. The formation of finger-like and tear-like macrovoids in hollow fibers can be attributed to the water intrusion and the fast mass exchange between the solvent in the polymer solution and water (non-solvent), since distilled water was used as bore fluid and outer coagulant in the spinning process. Water is a strong non-solvent, while NMP has weaker interaction towards PEI; hence, it formed instant phase de-mixing, which created the finger-like and tear-like macrovoids [42]. The finger-like macrovoids near the shell side were shorter than the ones near the lumen side (Figure 1b). This is because of the formation of thin skin dense layer on the outer surface which impeded the water intrusion process. In the spinning process, the as-spun hollow fiber went through an air-gap distance of $25 \mathrm{~cm}$ (Table 1), and then to the water coagulant bath; the solvent evaporated during this short time, which increased the viscosity of polymer solution near shell side. As a result, the thin dense skin layer was formed and the solvent/non-solvent exchange process was slowed down.
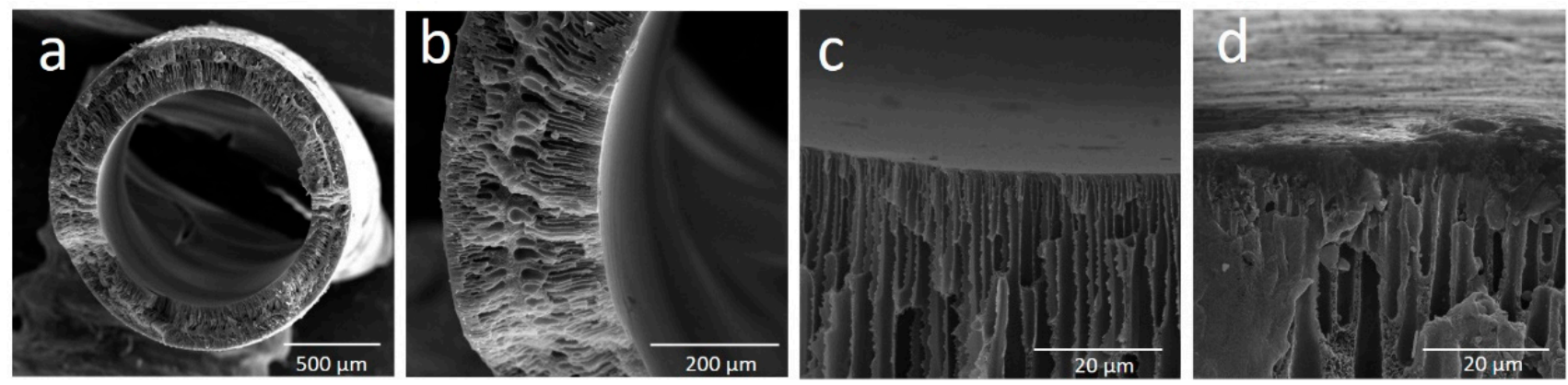

Figure 1. SEM pictures of uncoated PEI hollow fibers: (a) overall cross-section, (b) enlarged cross-section, (c) inner side, and (d) outer side.

Figure 2 shows the morphology of PDMS/PEI membranes prepared by using the dip-coating method. The overall cross-section of PDMS/PEI membrane was shown in Figure 2a. It is observed that a thin PDMS selective layer was formed on the outer surface of PEI hollow fibers (Figure 2b,c).

As it is shown in Figure 3, the coating time and the coating solution concentration affect the thickness of PDMS layer. When $15 \mathrm{wt} \%$ of PDMS solution was used, the thickness of PDMS layer at the bottom part of PDMS/PEI composite membrane increased from 3 to 4 $\mu \mathrm{m}$, along with the change of coating time from 1 to $7 \mathrm{~min}$. The further increase in coating time to 15 min did not change the thickness of PDMS layer (Figure 3a). The thickness of PDMS layer at the top part of PDMS/PEI composite membrane slightly increased from 1.9 to $2.5 \mu \mathrm{m}$, accompanied by the change of coating time from 1 to $15 \mathrm{~min}$ (Figure 3a). With an increase in coating time, more PDMS chains could diffuse and adhere onto the substrate surface and reach a stable state. Therefore, the PDMS layer thickness increased 
when the coating time increased from 1 to $7 \mathrm{~min}$, while it became constant with the further increase of coating time to $15 \mathrm{~min}$. The coating time has a more significant influence on the PDMS layer thickness at the bottom part than the top part of PDMS/PEI composite membrane. When the coating time is set as $10 \mathrm{~min}$, the thickness of PDMS layer at the top part and the bottom part of PDMS/PEI composite membrane increased from 1.5 and $2 \mu \mathrm{m}$ to 3.3 and $5.6 \mu \mathrm{m}$, along with the growth of PDMS concentration from 3 to $20 \mathrm{wt} \%$, respectively (Figure 3b). According to the Landau-Levich theory, the thickness of coating layer is positively proportional to the viscosity of coating solutions [43]. The viscosity of PDMS solution increased with the concentration increase of PDMS solution. As a result, the thickness of the PDMS layer augmented with an increase in PDMS concentration. It was reported in the literature that the thickness of the coating layer increased with the increase in the concentration of coating solution and coating time $[16,28,44,45]$. When comparing Figure $3 \mathrm{a}, \mathrm{b}$, it is found that the concentration of PDMS solution predominantly affected the thickness of PDMS selective layer. Furthermore, the thickness of PDMS layer at the bottom part is slightly higher than the thickness of PDMS layer at the top part. In the dip-coating process, the interplay of several parameters, e.g., viscous force, solvent evaporation and draining, surface tension, gravity, and hydrodynamic factors in the the layer deposition region, governs the layer thickness and the position of the drying front. The bottom part was always close to the solution reservoir, while the top part was relatively far from the coating solution. A wet film with higher concentration was formed at the drying front, due to the higher ratio of surface area to volume, which results in the drawing of solution from surrounding area. When a dry film was formed at the drying front, a capillary force appeared on the solution, resulting in the thickening of the coated film [46-49].
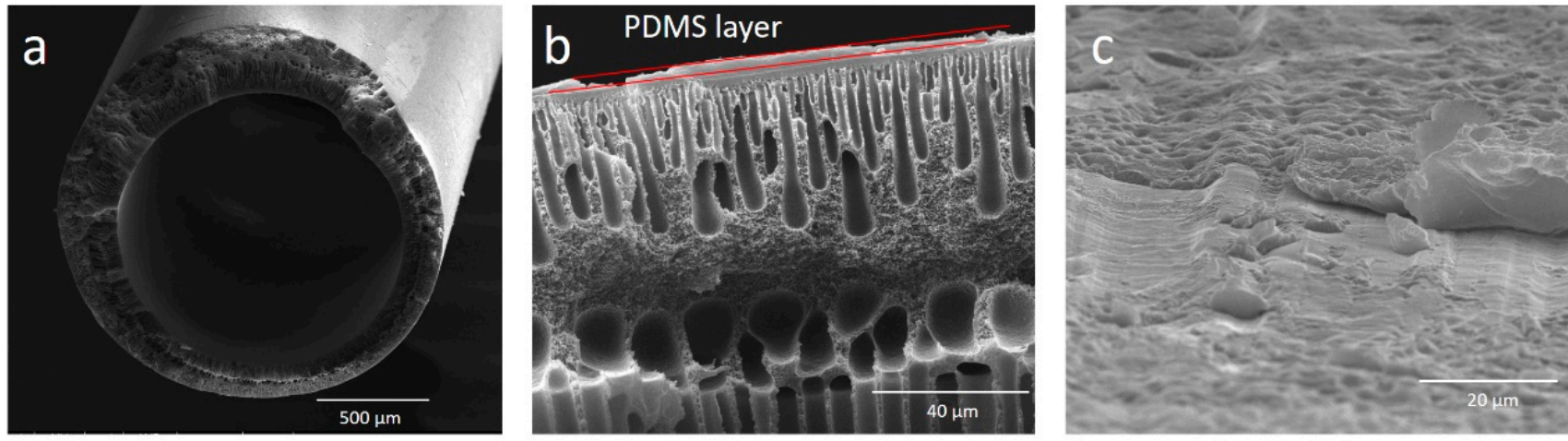

Figure 2. SEM pictures of polydimethysiloxane (PDMS)/PEI membrane prepared from $15 \mathrm{wt} \%$ PDMS solution at 10 min coating time: (a) overall cross-section, (b) enlarged cross-section, and (c) outer PDMS coating layer.

Figure 4 shows the EDX results of PDMS/PEI membranes prepared at various coating times and using various concentrations of PDMS solution. The detection of carbon, oxygen, and nitrogen can be attributed to the characteristics of PEI, which contains imide group in its chemical structure. The detection of silicon element indicates the PDMS was successfully coated on the outer surface of substrate. As it is shown in Figure 4a, with an increase in coating time, the atomic concentration of nitrogen and silicon decreased and increased, respectively, which indicates the more desirable formation of PDMS selective layer. When the coating time is over $10 \mathrm{~min}$, a dense PDMS layer completely covered the outer surface of support. These results are consistent with the results of gas permeance of PDMS/PEI membranes prepared at various coating time (Section 3.2.1). As the EDX results in Figure $4 \mathrm{~b}$ show, the atomic concentration of silicon increased significantly from $1.26 \%$ to $21.31 \%$, along with the change of coating solution from 3 to $20 \mathrm{wt} \%$. These results are also consistent with the results of PDMS layer thickness (Figure 3b) and gas permeance of PDMS/PEI membranes prepared from various concentrations of PDMS solution (Section 3.2.2). As discussed above, the silicon concentration increased with the growth of coating time and 
PDMS concentration, which is due to the formation of thicker PDMS layer and deposition of more PDMS chains on the support.

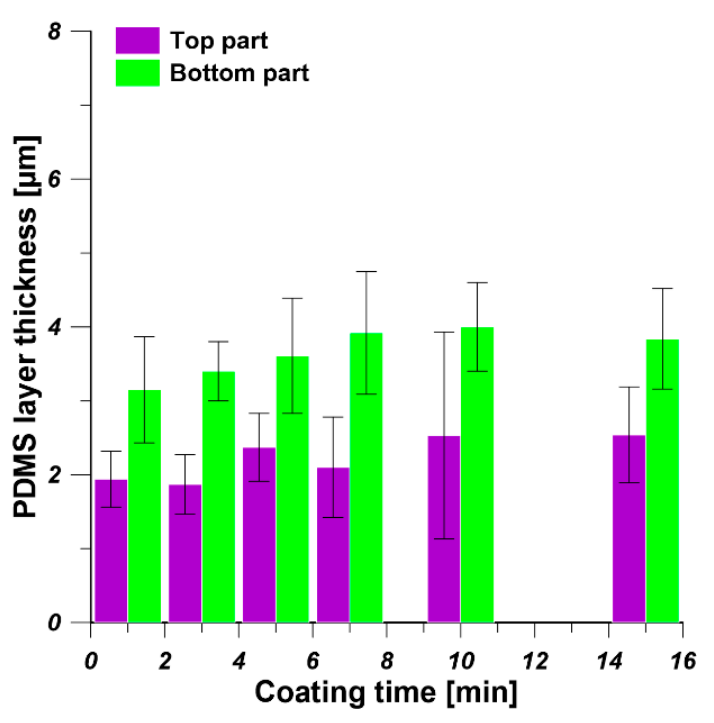

(a)

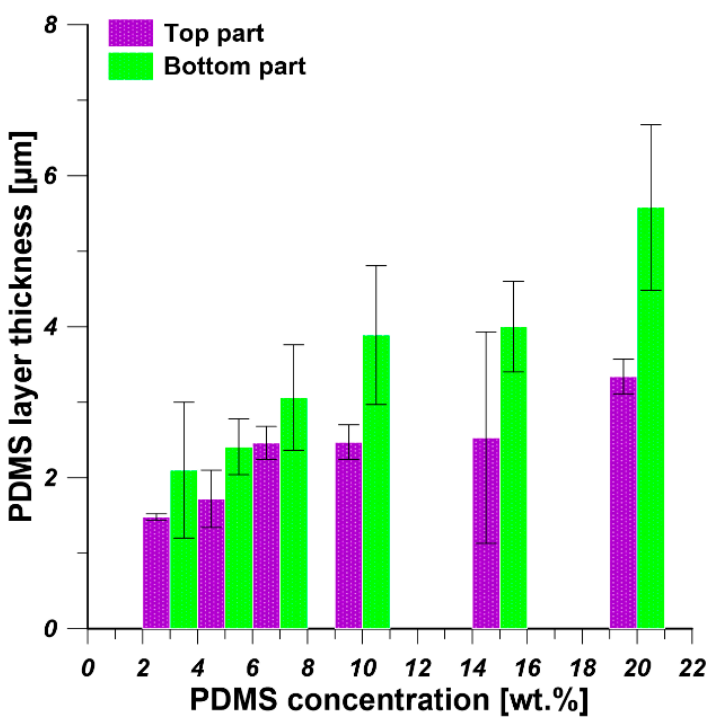

(b)

Figure 3. The thickness of PDMS selective layer: (a) the effect of coating time at constant concentration of PDMS solution equal to $15 \mathrm{wt} \%$; (b) the effect of PDMS concentration at constant coating time equal to $10 \mathrm{~min}$.

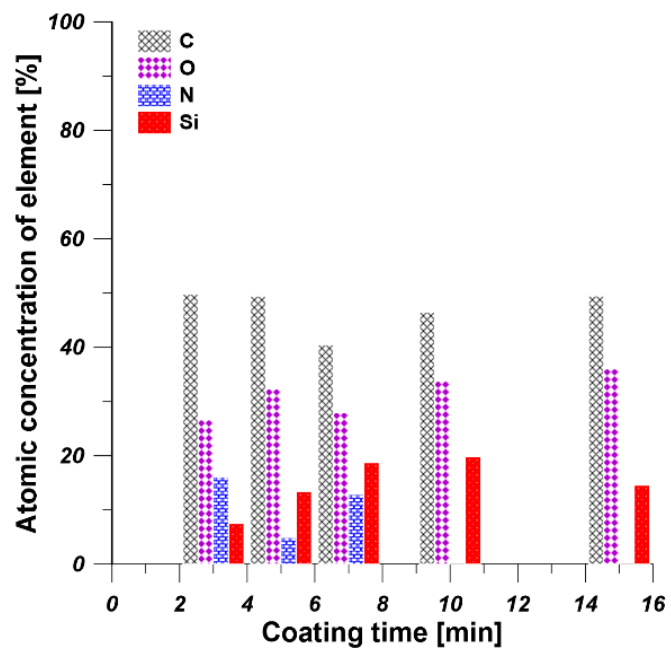

(a)

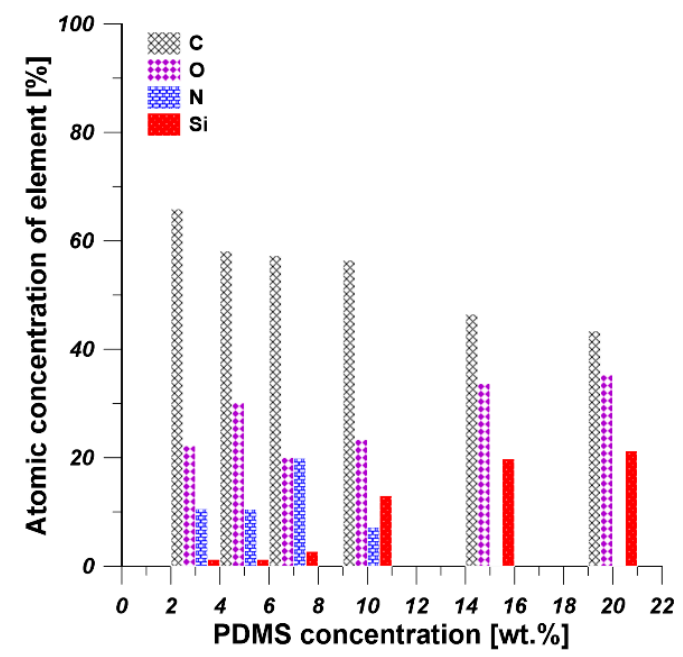

(b)

Figure 4. EDX surface mapping results for PDMS/PEI membranes fabricated (a) by changing the coating time, using PDMS concentration equal to $15 \mathrm{wt} \%$; (b) by using various PDMS concentrations at constant coating time equal to $10 \mathrm{~min}$.

\subsection{Gas-Separation Performance}

The prepared unmodified PEI hollow fibers were highly permeable to $\mathrm{CO}_{2}$ and $\mathrm{N}_{2}$, with the ideal selectivity close to 1 . To obtain a PDMS/PEI composite hollow-fiber membrane with high selectivity and reasonable gas permeance via the dip-coating method, the optimization of coating conditions plays a crucial role. The influence of the chosen coating conditions on the gas-separation performance of PDMS/PEI composite hollow-fiber membrane is discussed in this section. 


\subsubsection{The Effect of Coating Time}

To investigate the influence of coating time on the gas permeance, PDMS/PEI composite membranes were fabricated by immersing PEI supports in $15 \mathrm{wt} \%$ of PDMS solution at various time from 0.5 to $15 \mathrm{~min}$ and cured at $25{ }^{\circ} \mathrm{C}$. Figure $5 \mathrm{a}$ shows the trends of $\mathrm{CO}_{2}$ and $\mathrm{N}_{2}$ permeances, and the ideal selectivity of PDMS/PEI membranes prepared at various coating times. It can be realized that the $\mathrm{CO}_{2}$ and $\mathrm{N}_{2}$ permeances decreased significantly when the coating time changed from 0.5 to $5 \mathrm{~min}$. Then the $\mathrm{CO}_{2}$ permeance continued to decrease slightly, while the $\mathrm{N}_{2}$ permeance leveled off for the coating time in the range of 5 to $15 \mathrm{~min}$. This is because the kinetic diameter of $\mathrm{N}_{2}$ molecule $(0.36 \mathrm{~nm})$ is larger than that of $\mathrm{CO}_{2}$ molecule $(0.33 \mathrm{~nm})$. Moreover, the $\mathrm{CO}_{2}$ molecules possess higher affinity to PDMS [50]. Hence, $\mathrm{CO}_{2}$ molecules are transported much faster than $\mathrm{N}_{2}$ ones, and they are more sensitive to the thickness change of PDMS layer (Figure 3a). On the other hand, the $\mathrm{CO}_{2} / \mathrm{N}_{2}$ ideal selectivity increased to the maximal values of 21 , when the coating time approached $10 \mathrm{~min}$. Afterwards, the $\mathrm{CO}_{2} / \mathrm{N}_{2}$ ideal selectivity decreased only slightly. This is caused by a fact that with an increase of coating time, the defect-free PDMS layer was formed, resulting in the increased value of the ideal selectivity. However, the coated PDMS might be re-dissolved in the solvent when a longer coating time is applied. As a result, defects might be formed and the selectivity was reduced. It is found that 10 min was the optimal coating time for the preparation of PDMS/PEI membranes with a high gas-separation performance. Similar results were also found by Chen et al. [35]. The thickness of PDMS layer of PDMS/PEI composite membrane prepared from $15 \mathrm{wt} \%$ of PDMS solution at various coating times was measured. Figure $5 \mathrm{~b}$ shows the influence of PDMS layer thickness on $\mathrm{CO}_{2}$ permeance; it can be seen that $\mathrm{CO}_{2}$ permeance drops with the formation of thicker PDMS layer due to the increased mass transfer resistance [51,52]. According to the solution-diffusion model, the gas permeance is inversely proportional to the thickness of selective layer [53]. It can be seen in Figure $5 b$ that the $\mathrm{CO}_{2}$ permeance is linearly proportional to the reciprocal of PDMS layer thickness, which revealed the hypothesis that the gas transport through the PDMS layer obeys the solution-diffusion mechanism.

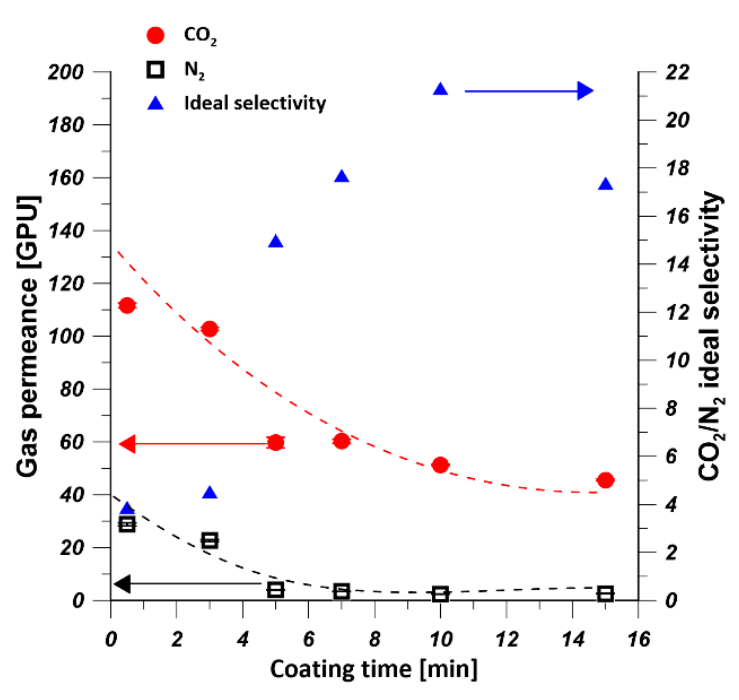

(a)

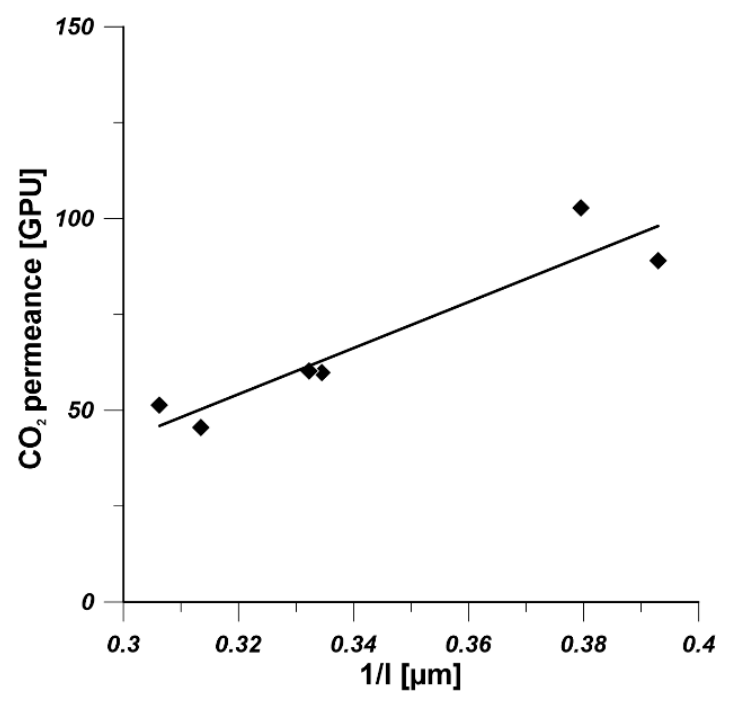

(b)

Figure 5. (a) The effect of coating time on gas permeance and ideal selectivity of PDMS/PEI membranes prepared from $15 \mathrm{wt} \%$ of PDMS solution (the dashed line indicates only the trend of gas permeance change). (b) The influence of PDMS layer thickness (l) on $\mathrm{CO}_{2}$ permeance of PDMS/PEI membranes prepared from various $15 \mathrm{wt} \%$ of PDMS solution at various coating time (the average thickness of PDMS layer was calculated based on the thicknesses of PDMS layer at the top and bottom parts). 


\subsubsection{The Effect of PDMS Concentration}

As it is shown in Figure 6a, the $\mathrm{CO}_{2}$ permeance and $\mathrm{N}_{2}$ permeance dramatically decreased from 1360 GPU to 49 GPU and 2.5 GPU, respectively, when the PDMS concentration changed from $1.5 \mathrm{wt} \%$ to $10 \mathrm{wt} \%$. Then the $\mathrm{CO}_{2}$ permeance was constant at 50 GPU but slightly decreased to 40 GPU with the change of PDMS concentration from $15 \mathrm{wt} \%$ to $20 \mathrm{wt} \%$. However, $\mathrm{N}_{2}$ permeance was leveled off at 2.4 GPU when the PDMS concentration was between 10 and $20 \mathrm{wt} \%$. The decrease in gas permeance was attributed to the increase in PDMS layer thickness (Figure $3 b$ ). The $\mathrm{CO}_{2} / \mathrm{N}_{2}$ ideal selectivity increased to the maximal values of 21 , when the PDMS concentration increased to $15 \mathrm{wt} \%$. However, it decreased when $20 \mathrm{wt} \%$ PDMS solution was used for coating. When the PDMS solutions of $1.5,3,5$, and $7 \mathrm{wt} \%$ were used as coating solution, defects might be formed on the PDMS selective layer. These findings are consistent with the EDX mapping results (Figure $4 \mathrm{~b}$ ). When $20 \mathrm{wt} \%$ of PDMS solution was used as coating solution, the prepared composite hollow-fiber membrane possessed the lowest $\mathrm{CO}_{2}$ permeance owing to the formation of a thicker PDMS selective layer (Figure 3b). The decrease of $\mathrm{CO}_{2} / \mathrm{N}_{2}$ ideal selectivity can be explained by the relatively larger decrease in $\mathrm{CO}_{2}$ permeance comparing to the $\mathrm{N}_{2}$ permeance which resulted from the sensitivity of $\mathrm{CO}_{2}$ to the change of PDMS layer thickness. Chong et al. [54] found similar results where PDMS/PSf composite hollow-fiber membranes experienced lower $\mathrm{O}_{2}$ permeance and $\mathrm{O}_{2} / \mathrm{N}_{2}$ selectivity due to the formation of thicker PDMS layer which increases the mass transfer resistance. The thickness of PDMS layer of PDMS/PEI composite membrane prepared from various concentrations of PDMS solution at coating time equal to $10 \mathrm{~min}$ was measured. As it is shown in Figure $6 \mathrm{~b}, \mathrm{CO}_{2}$ permeance is linearly proportional to the reciprocal of PDMS layer thickness which is in good agreement with solution-diffusion model [53]. The decrease in $\mathrm{CO}_{2}$ permeance was attributed to an increase in the thickness of PDMS selective layer [51,53].

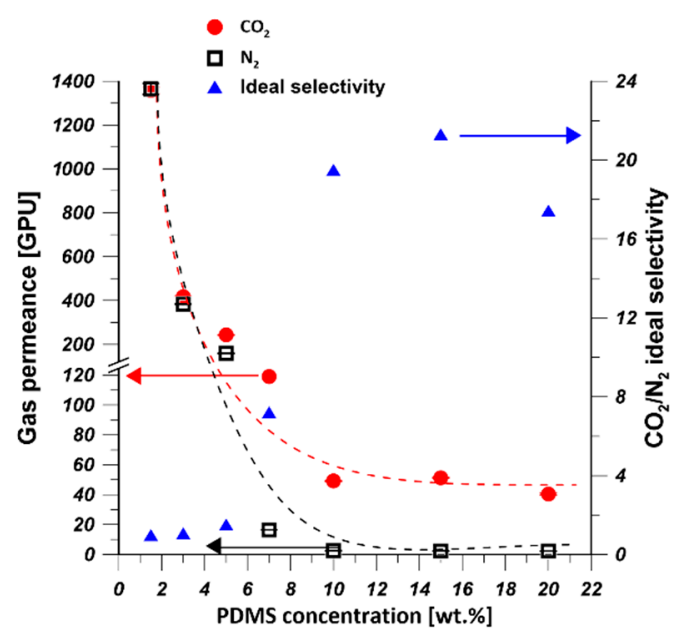

(a)

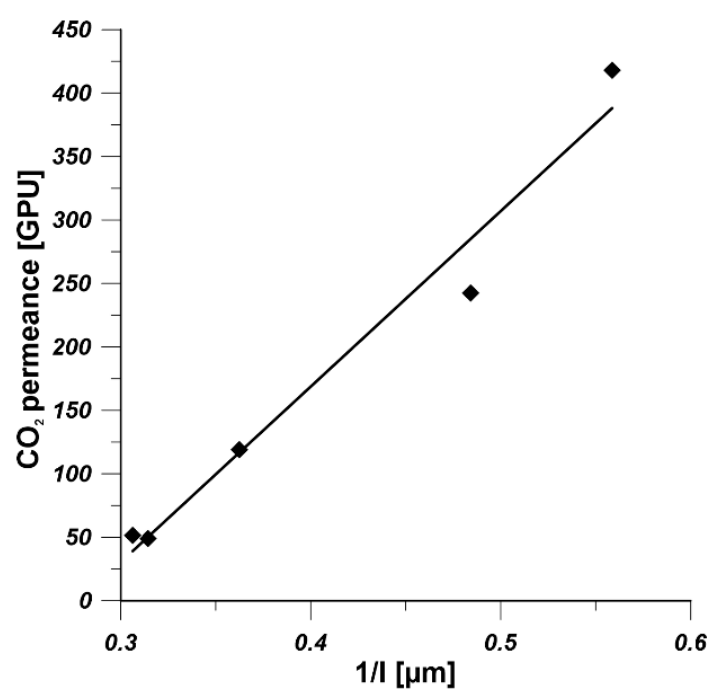

(b)

Figure 6. (a) The effect of PDMS concentration on gas permeance and ideal selectivity of PDMS/PEI membranes prepared at coating time of $10 \mathrm{~min}$ (the dashed line only indicates the trend of gas permeance change). (b) The influence of PDMS layer thickness on $\mathrm{CO}_{2}$ permeance of PDMS/PEI membranes prepared from various PDMS concentrations, at a coating time of $10 \mathrm{~min}$ (the average thickness of PDMS layer was calculated based on the thickness of PDMS layer at the top and bottom parts).

\subsubsection{The Effect of the Curing Temperature}

To investigate the effect of curing temperature on the gas permeance of PDMS/PEI membranes, $15 \mathrm{wt} \%$ of PDMS solution was coated on PEI hollow-fiber substrate for $10 \mathrm{~min}$. Subsequently, the coated hollow fibers were transferred to an oven and crosslinked at vari- 
ous temperatures, i.e., $25,50,80$, and $130^{\circ} \mathrm{C}$. As it is shown in Figure 7 , the gas permeances of $\mathrm{CO}_{2}$ and $\mathrm{N}_{2}$ experienced an increase and decrease trend with the increase in annealing temperature. The PDMS/PEI composite hollow-fiber membranes cured at $25{ }^{\circ} \mathrm{C}$ showed the highest $\mathrm{CO}_{2} / \mathrm{N}_{2}$ selectivity. Therefore, $25{ }^{\circ} \mathrm{C}$ was used as the curing temperature and membranes were annealed in air at $25^{\circ} \mathrm{C}$. Madaeni et al. [28] observed that the $\mathrm{CO}_{2}$ permeance and $\mathrm{CO}_{2} / \mathrm{N}_{2}$ selectivity of PDMS/PES flat sheet membrane decreased slightly with the increase in curing temperature from $25^{\circ} \mathrm{C}$ to $200^{\circ} \mathrm{C}$. Kargari et al. [21] found that the curing temperature has little effect on the $\mathrm{H}_{2}$ and $\mathrm{CH}_{4}$ permeances and selectivity of PDMS/PEI flat sheet membranes. It can be seen that higher curing temperature could not enhance the gas-separation performance of PDMS coated composite membranes. This is because the viscosity of coating solution decreased with the increase in curing temperature, which resulted in the weakened adhesion between PDMS chain and substrate and the formation of undesirable defects [43].

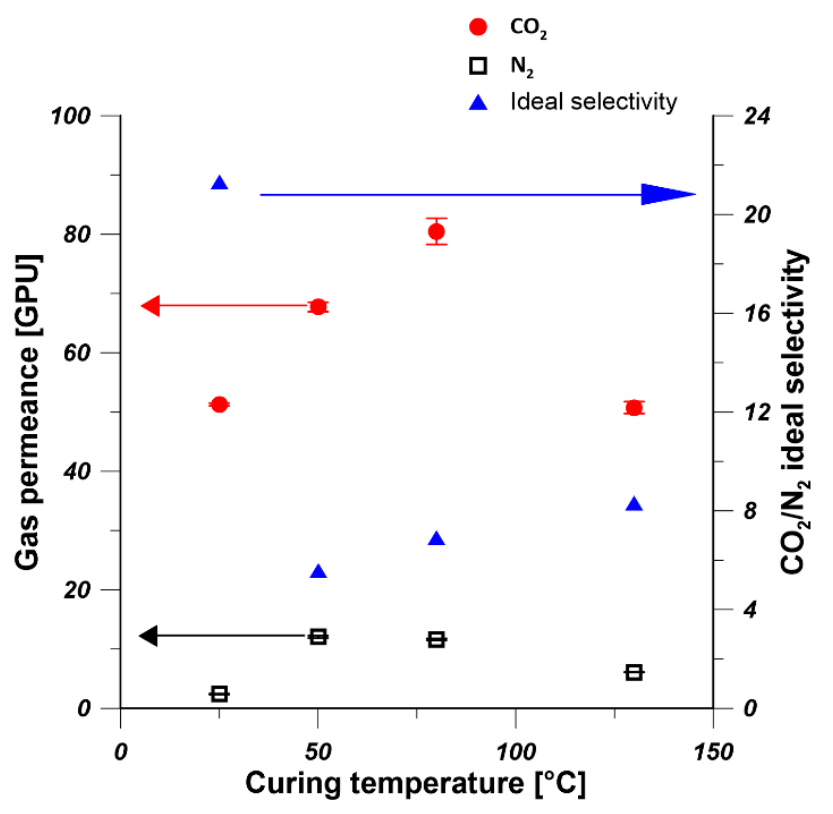

Figure 7. Effect of curing temperature on gas permeance and ideal selectivity of PDMS/PEI membranes (PDMS concentration-15 $\mathrm{wt} \%$ and coating time $-10 \mathrm{~min}$ ).

\subsubsection{The Effect of the Multiple Coating of PDMS}

To investigate the influence of the multiple coating of PDMS layer on the gas permeance of PDMS/PEI membranes, one, two, and three PDMS layers were coated on the hollow-fiber substrate by using $15 \mathrm{wt} \%$ PDMS solution for $10 \mathrm{~min}$ at $25^{\circ} \mathrm{C}$. As it is shown in Figure 8 , when the PDMS coating changed from one time to three times, the $\mathrm{N}_{2}$ permeance was practically constant, while the $\mathrm{CO}_{2}$ permeance decreased due to the increase in the thickness of PDMS layer from 3.3 to $5.5 \mu \mathrm{m}$. Therefore, $\mathrm{CO}_{2} / \mathrm{N}_{2}$ ideal selectivity decreased with the increase in the number of PDMS layers. Similar findings were presented in the work of Selyanchyn et al. [52]. They prepared Pebax/PDMS/porous support thin-film composite flat-sheet membranes, where a PDMS layer was used as a gutter layer and a Pebax layer was used as the selective layer. It was reported that when the thickness of Pebax and PDMS layer increased from 0.29 and $2.3 \mu \mathrm{m}$ to 0.39 and $10.8 \mu \mathrm{m}$, respectively, the $\mathrm{CO}_{2}$ permeance and $\mathrm{CO}_{2} / \mathrm{N}_{2}$ selectivity decreased from $300 \mathrm{GPU}$ and 43 to $180 \mathrm{GPU}$ and 35, respectively. The decrease in gas permeance is owing to the increase of thickness of selective layer. The increased thickness of selective layer imparted more significant influence on $\mathrm{CO}_{2}$ permeance that it on $\mathrm{N}_{2}$, which resulted in the decrease in $\mathrm{CO}_{2} / \mathrm{N}_{2}$ selectivity. This is because larger gas molecules are preferentially transported through PDMS selective layer [55]. However, Kargari et al. [21] found that when the number of coating layers increased, the $\mathrm{H}_{2}$ permeance decreased, while the $\mathrm{H}_{2} / \mathrm{CH}_{4}$ selectivity increased. 
This is because the defect-free coating layer was developed as the number of coating layer increased, which finally led to a better performance.

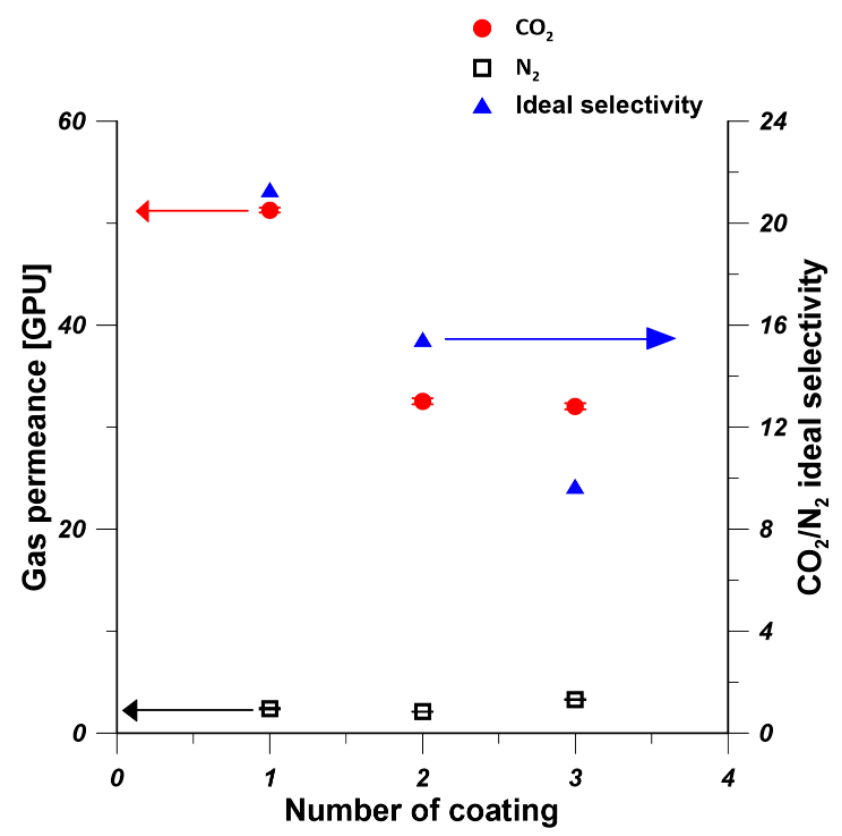

Figure 8. Effect of the number of coating layers on gas permeance and ideal selectivity of PDMS/PEI membranes (PDMS concentration-15 $\mathrm{wt} \%$ and coating time $-10 \mathrm{~min}$ ).

\section{Comparison of $\mathrm{CO}_{2}$ and $\mathrm{N}_{2}$ Separation with Literature Data}

Table 3 summarizes the previously reported works in which thin-film composite membranes have been prepared for $\mathrm{CO}_{2} / \mathrm{N}_{2}$ separation. Pebax or PDMS solution with low concentration was generally used as coating solution for the formation of selective layer on porous substrate $[34,56]$. When the prepared membranes possessed high $\mathrm{CO}_{2}$ permeance, the $\mathrm{CO}_{2} / \mathrm{N}_{2}$ selectivity was low $[24,34]$. The prepared membranes in this work possess satisfying $\mathrm{CO}_{2} / \mathrm{N}_{2}$ separation performance in comparison with the examples from the literature [56], which indicates the PDMS/PEI membranes were successfully fabricated.

Table 3. Comparison of the thin film composite hollow-fiber membranes for $\mathrm{CO}_{2} / \mathrm{N}_{2}$ separation (HF-hollow fiber and FT-flat sheet).

\begin{tabular}{|c|c|c|c|c|c|}
\hline \multirow[t]{2}{*}{ Membrane } & \multirow[t]{2}{*}{ Configuration } & \multicolumn{2}{|c|}{$\begin{array}{c}\text { Pure Gas Permeance } \\
\text { (GPU) }\end{array}$} & \multirow[t]{2}{*}{$\mathrm{CO}_{2} / \mathrm{N}_{2}$} & \multirow[t]{2}{*}{ Reference } \\
\hline & & $\mathrm{CO}_{2}$ & $\mathbf{N}_{2}$ & & \\
\hline $3 \mathrm{wt} \% \mathrm{PDMS} / \mathrm{PAN}$ & $\mathrm{HF}$ & 2494 & 241 & 10.4 & [34] \\
\hline $2 \mathrm{wt} \%$ PDMS/PAN & $\mathrm{HF}$ & 2680 & 360 & 9 & {$[34]$} \\
\hline $3 w t \%$ PDMS/PSf & $\mathrm{HF}$ & 55 & 1.56 & 35 & [56] \\
\hline $3 w t \%$ PDMS $/ P S f$ & $\mathrm{HF}$ & 59 & 1.60 & 37 & [56] \\
\hline $0.3 w \mathrm{t} \%$ PDMS/PAN & $\mathrm{HF}$ & 5138 & 485 & 11 & [24] \\
\hline 3 wt $\%$ PDMS/PSf & $\mathrm{HF}$ & 200 & 6 & 33 & [57] \\
\hline $3 \mathrm{wt} \%$ PDMS/PES-PI & $\mathrm{HF}$ & 60 & 1.54 & 39 & [58] \\
\hline $3 \mathrm{wt} \%$ PDMS/PSf & $\mathrm{HF}$ & 64 & 2 & 32 & [59] \\
\hline PEBA/PDMS/PEI & FT & 172 & 3.64 & 47 & [29] \\
\hline PDMS/PEBA/PDMS/PEI & FT & 157 & 2.46 & 64 & [29] \\
\hline $3 w t \%$ Pebax/PSf & $\mathrm{HF}$ & 23 & 0.64 & 36 & [56] \\
\hline $3 w t \%$ Pebax/PSf & $\mathrm{HF}$ & 30 & 0.76 & 39 & [56] \\
\hline $5 \mathrm{wt} \%$ Pebax/PEI & $\mathrm{HF}$ & 48 & 2.00 & 24 & [60] \\
\hline $15 \mathrm{wt} \%$ PDMS/PEI & $\mathrm{HF}$ & 51 & 2.4 & 21 & This work \\
\hline
\end{tabular}




\section{Conclusions}

PDMS/PEI composite hollow fiber membranes were successfully fabricated by using the dip-coating method. The thickness of PDMS layer was influenced by the concentration of coating solution and the coating time. The increase in coating time and the concentration of PDMS solution resulted in the decrease in gas permeance, due to the formation of defectfree PDMS layer and the increase in its thickness. The relation between gas permeance and PDMS layer thickness followed the solution-diffusion model. The increase in curing temperature and the number of coating layer imparted adverse effects on the gas-separation performance. The composite hollow fiber membrane prepared from $15 \mathrm{wt} . \%$ PDMS solution at 10 min coating time showed the best gas-separation performance with $\mathrm{CO}_{2}$ permeance of $51 \mathrm{GPU}$ and $\mathrm{CO}_{2} / \mathrm{N}_{2}$ selectivity of 21 . The gas-separation performance of PDMS/PEI composite hollow fiber membrane is comparable to literature ones.

The prepared PDMS/PEI composite hollow fiber membranes followed the tradeoff relationship between permeance and selectivity [26]. To enhance the gas-separation performance by increasing the gas permeance and selectivity simultaneously, 2D nanomaterials, such as surface-modified graphene oxide (GO) containing $\mathrm{CO}_{2}$-philic functional groups [61-63] and nitrogen-doped graphene nanosheets [64,65], will be incorporated in the selective coating layer in the further works. Moreover, the conditions for the preparation of mixed matrix hollow fiber membranes [66] will be optimized by using chemometric methods [67].

Author Contributions: Conceptualization, G.L. and W.K.; data curation, G.L. and W.K.; formal analysis, G.L., K.K., J.K., A.T., and W.K.; funding acquisition, G.L. and W.K.; investigation, G.L. and K.K.; methodology, G.L., K.K., A.T., and A.S.; supervision, J.K. and W.K.; Validation, A.T. and A.S.; Visualization, G.L., and K.K.; writing—original draft, G.L.; writing—review and editing, J.K., A.T., A.S., and W.K. All authors have read and agreed to the published version of the manuscript.

Funding: This work was supported by the Young Researcher grant for PhD Students of Nicolaus Copernicus University in Torun, Poland (Faculty of Chemistry, 492/2020).

Data Availability Statement: The data presented in this study are available on request from the corresponding author.

Conflicts of Interest: The authors declare no conflict of interest.

\section{References}

1. Chen, W.; Zhang, Z.; Hou, L.; Yang, C.; Shen, H.; Yang, K.; Wang, Z. Metal-organic framework MOF-801/PIM-1 mixed-matrix membranes for enhanced $\mathrm{CO}_{2} / \mathrm{N}_{2}$ separation performance. Sep. Purif. Technol. 2020, 250, 117198. [CrossRef]

2. Ning, H.; Yang, Z.; Wang, D.; Meng, Z.; Li, Y.; Ju, X.; Wang, C. Graphene-based semi-coke porous carbon with N-rich hierarchical sandwich-like structure for efficient separation of $\mathrm{CO}_{2} / \mathrm{N}_{2}$. Microporous Mesoporous Mater. 2021, 311, 110700. [CrossRef]

3. Ding, R.; Zheng, W.; Yang, K.; Dai, Y.; Ruan, X.; Yan, X.; He, G. Amino-functional ZIF-8 nanocrystals by microemulsion based mixed linker strategy and the enhanced $\mathrm{CO}_{2} / \mathrm{N}_{2}$ separation. Sep. Purif. Technol. 2020, 236, 116209. [CrossRef]

4. Aydani, A.; Brunetti, A.; Maghsoudi, H.; Barbieri, G. $\mathrm{CO}_{2}$ separation from binary mixtures of $\mathrm{CH}_{4}, \mathrm{~N}_{2}$, and $\mathrm{H}_{2}$ by using SSZ-13 zeolite membrane. Sep. Purif. Technol. 2021, 256, 117796. [CrossRef]

5. Chang, J.; Hou, C.; Wan, D.; Zhang, X.; Xu, B.; Tian, H.; Wang, X.; Guo, Q. Enhanced $\mathrm{CO}_{2}$ adsorption capacity of bi-amine co-tethered flue gas desulfurization gypsum with water of hydration. J. $\mathrm{CO}_{2}$ Util. 2020, 35, 115-125. [CrossRef]

6. Riboldi, L.; Bolland, O. Overview on Pressure Swing Adsorption (PSA) as $\mathrm{CO}_{2}$ Capture Technology: State-of-the-Art, Limits and Potentials. Energy Procedia 2017, 114, 2390-2400. [CrossRef]

7. Yousef, A.M.; El-Maghlany, W.M.; Eldrainy, Y.A.; Attia, A. New approach for biogas purification using cryogenic separation and distillation process for $\mathrm{CO}_{2}$ capture. Energy 2018, 156, 328-351. [CrossRef]

8. Li, G.; Kujawski, W.; Válek, R.; Koter, S. A review-The development of hollow fibre membranes for gas separation processes. Int. J. Greenh. Gas Control. 2021, 104, 103195. [CrossRef]

9. Xiao, Y.; Chung, T.-S. Grafting thermally labile molecules on cross-linkable polyimide to design membrane materials for natural gas purification and $\mathrm{CO}_{2}$ capture. Energy Environ. Sci. 2011, 4, 201-208. [CrossRef]

10. Xie, K.; Fu, Q.; Qiao, G.G.; Webley, P.A. Recent progress on fabrication methods of polymeric thin film gas separation membranes for $\mathrm{CO}_{2}$ capture. J. Membr. Sci. 2019, 572, 38-60. [CrossRef]

11. Shi, Y.; Liang, B.; Lin, R.-B.; Zhang, C.; Chen, B. Gas Separation via Hybrid Metal-Organic Framework/Polymer Membranes. Trends Chem. 2020, 2, 254-269. [CrossRef] 
12. Tham, H.M.; Wang, K.Y.; Hua, D.; Japip, S.; Chung, T.-S. From ultrafiltration to nanofiltration: Hydrazine cross-linked polyacrylonitrile hollow fiber membranes for organic solvent nanofiltration. J. Membr. Sci. 2017, 542, 289-299. [CrossRef]

13. Gao, J.; Thong, Z.; Wang, K.Y.; Chung, T.-S. Fabrication of loose inner-selective polyethersulfone (PES) hollow fibers by one-step spinning process for nanofiltration (NF) of textile dyes. J. Membr. Sci. 2017, 541, 413-424. [CrossRef]

14. Baker, R.W. Membrane Technology and Applications; John Wiley \& Sons: Hoboken, NJ, USA, 2012.

15. Karimi, S.; Firouzfar, E.; Khoshchehreh, M.R. Assessment of gas separation properties and $\mathrm{CO}_{2}$ plasticization of polysulfone/polyethylene glycol membranes. J. Pet. Sci. Eng. 2019, 173, 13-19. [CrossRef]

16. Chong, K.C.; Lai, S.O.; Lau, W.J.; Thiam, H.S.; Ismail, A.F.; Roslan, R.A. Preparation, characterization, and performance evaluation of polysulfone hollow fiber membrane with PEBAX or PDMS coating for oxygen enhancement process. Polymers 2018, 10, 126. [CrossRef]

17. Wang, M.; Wang, Z.; Li, S.; Zhang, C.; Wang, J.; Wang, S. A high performance antioxidative and acid resistant membrane prepared by interfacial polymerization for $\mathrm{CO}_{2}$ separation from flue gas. Energy Environ. Sci. 2013, 6, 539-551. [CrossRef]

18. Shamsabadi, A.A.; Kargari, A.; Babaheidari, M.B. Preparation, characterization and gas permeation properties of PDMS/PEI composite asymmetric membrane for effective separation of hydrogen from $\mathrm{H}_{2} / \mathrm{CH}_{4}$ mixed gas. Int. J. Hydrog. Energy 2014, 39, 1410-1419. [CrossRef]

19. Peng, N.; Chung, T.-S.; Chng, M.L.; Aw, W. Evolution of ultra-thin dense-selective layer from single-layer to dual-layer hollow fibers using novel Extem ${ }^{\circledR}$ polyetherimide for gas separation. J. Membr. Sci. 2010, 360, 48-57. [CrossRef]

20. Mousavi, S.A.; Aboosadi, Z.A.; Mansourizadeh, A.; Honarvar, B. Surface modified porous polyetherimide hollow fiber membrane for sweeping gas membrane distillation of dyeing wastewater. Colloids Surf. A Physicochem. Eng. Asp. 2020, 125439. [CrossRef]

21. Kargari, A.; Shamsabadi, A.A.; Babaheidari, M.B. Influence of coating conditions on the $\mathrm{H}_{2}$ separation performance from $\mathrm{H}_{2} / \mathrm{CH}_{4}$ gas mixtures by the PDMS/PEI composite membrane. Int. J. Hydrog 2014, 39, 6588-6597. [CrossRef]

22. Choi, S.-H.; Jansen, J.C.; Tasselli, F.; Barbieri, G.; Drioli, E. In-line formation of chemically cross-linked P84 ${ }^{\circledR}$ co-polyimide hollow fibre membranes for $\mathrm{H}_{2} / \mathrm{CO}_{2}$ separation. Sep. Purif. Technol. 2010, 76, 132-139. [CrossRef]

23. Roy, P.K.; Kumar, K.; Thakkar, F.M.; Pathak, A.D.; Ayappa, K.G.; Maiti, P.K. Investigations on 6FDA/BPDA-DAM polymer melt properties and $\mathrm{CO}_{2}$ adsorption using molecular dynamics simulations. J. Membr. Sci. 2020, 613, 118377. [CrossRef]

24. Liang, C.Z.; Yong, W.F.; Chung, T.-S. High-performance composite hollow fiber membrane for flue gas and air separations. J. Membr. Sci. 2017, 541, 367-377. [CrossRef]

25. Fam, W.; Mansouri, J.; Li, H.; Chen, V. Improving $\mathrm{CO}_{2}$ separation performance of thin film composite hollow fiber with Pebax ${ }^{\circledR}$ 1657/ionic liquid gel membranes. J. Membr. Sci. 2017, 537, 54-68. [CrossRef]

26. Robeson, L.M. The upper bound revisited. J. Membr. Sci. 2008, 320, 390-400. [CrossRef]

27. Liang, C.Z.; Chung, T.-S.; Lai, J.-Y. A review of polymeric composite membranes for gas separation and energy production. Prog. Polym. Sci. 2019, 97, 101141. [CrossRef]

28. Madaeni, S.; Badieh, M.M.S.; Vatanpour, V. Effect of coating method on gas separation by PDMS/PES membrane. Polym. Eng. Sci. 2013, 53, 1878-1885. [CrossRef]

29. Ren, X.; Ren, J.; Li, H.; Feng, S.; Deng, M. Poly (amide-6-b-ethylene oxide) multilayer composite membrane for carbon dioxide separation. Int. J. Greenh. Gas Control. 2012, 8, 111-120. [CrossRef]

30. Liang, C.Z.; Chung, T.-S. Robust thin film composite PDMS/PAN hollow fiber membranes for water vapor removal from humid air and gases. Sep. Purif. Technol. 2018, 202, 345-356. [CrossRef]

31. Wong, K.C.; Goh, P.S.; Ismail, A.F. Gas separation performance of thin film nanocomposite membranes incorporated with polymethyl methacrylate grafted multi-walled carbon nanotubes. Int. Biodeterior. Biodegrad. 2015, 102, 339-345. [CrossRef]

32. Albo, J.; Wang, J.; Tsuru, T. Gas transport properties of interfacially polymerized polyamide composite membranes under different pre-treatments and temperatures. J. Membr. Sci. 2014, 449, 109-118. [CrossRef]

33. Basu, S.; Balakrishnan, M. Polyamide thin film composite membranes containing ZIF-8 for the separation of pharmaceutical compounds from aqueous streams. Sep. Purif. Technol. 2017, 179, 118-125. [CrossRef]

34. Li, P.; Chen, H.Z.; Chung, T.-S. The effects of substrate characteristics and pre-wetting agents on PAN-PDMS composite hollow fiber membranes for $\mathrm{CO}_{2} / \mathrm{N}_{2}$ and $\mathrm{O}_{2} / \mathrm{N}_{2}$ separation. J. Membr. Sci. 2013, 434, 18-25. [CrossRef]

35. Chen, H.Z.; Thong, Z.; Li, P.; Chung, T.-S. High performance composite hollow fiber membranes for $\mathrm{CO}_{2} / \mathrm{H}_{2}$ and $\mathrm{CO}_{2} / \mathrm{N}_{2}$ separation. Int. J. Hydrog. 2014, 39, 5043-5053. [CrossRef]

36. Jo, E.-S.; An, X.; Ingole, P.G.; Choi, W.-K.; Park, Y.-S.; Lee, H.-K. $\mathrm{CO}_{2} / \mathrm{CH}_{4}$ separation using inside coated thin film composite hollow fiber membranes prepared by interfacial polymerization. Chin. J. Chem. Eng. 2017, 25, 278-287. [CrossRef]

37. Xiao, B.; Huang, Q.; Chen, H.; Chen, X.; Long, G. A fractal model for capillary flow through a single tortuous capillary with roughened surfaces in fibrous porous media. Fractals 2021, 29, 2150017. [CrossRef]

38. Ghobadi, J.; Ramirez, D.; Khoramfar, S.; Kabir, M.M.; Jerman, R.; Saeed, M. Mathematical modeling of $\mathrm{CO}_{2}$ separation using different diameter hollow fiber membranes. Int. J. Greenh. Gas Control. 2021, 104, 103204. [CrossRef]

39. Li, G.; Kujawski, W.; Knozowska, K.; Kujawa, J. The effects of PEI hollow fiber substrate characteristics on PDMS/PEI hollow fiber membranes for $\mathrm{CO}_{2} / \mathrm{N}_{2}$ separation. Membranes 2021, 11, 56. [CrossRef] [PubMed]

40. Jamil, A.; Ching, O.P.; Shariff, A.M. Mixed matrix hollow fibre membrane comprising polyetherimide and modified montmorillonite with improved filler dispersion and $\mathrm{CO}_{2} / \mathrm{CH}_{4}$ separation performance. Appl. Clay Sci. 2017, 143, 115-124. [CrossRef] 
41. DashtArzhandi, M.R.; Ismail, A.F.; Matsuura, T.; Ng, B.C.; Abdullah, M.S. Fabrication and characterization of porous polyetherimide/montmorillonite hollow fiber mixed matrix membranes for $\mathrm{CO}_{2}$ absorption via membrane contactor. Chem. Eng. J. 2015, 269, 51-59. [CrossRef]

42. Jamil, A.; Oh, P.C.; Shariff, A.M. Polyetherimide-montmorillonite mixed matrix hollow fibre membranes: Effect of inorganic/organic montmorillonite on $\mathrm{CO}_{2} / \mathrm{CH}_{4}$ separation. Sep. Purif. Technol. 2018, 206, 256-267. [CrossRef]

43. Tang, X.; Yan, X. Dip-coating for fibrous materials: Mechanism, methods and applications. J. Sol Gel Sci. Technol. 2017, 81, 378-404. [CrossRef]

44. Madaeni, S.S.; Moradi, A.; Kazemi, V. PDMS coated polyethersulphone composite membranes for separation of propylene and nitrogen gas mixtures. Iran. Polym. J. 2009, 18, 873-879.

45. Wang, L.; Li, Y.; Li, S.; Ji, P.; Jiang, C. Preparation of composite poly(ether block amide) membrane for $\mathrm{CO}_{2}$ capture. J. Energy Chem. 2014, 23, 717-725. [CrossRef]

46. Campana, D.M.; Ubal, S.; Giavedoni, M.D.; Saita, F.A. Influence of Surfactants on Dip Coating of Fibers: Numerical Analysis. Ind. Eng. Chem. Res. 2016, 55, 5770-5779. [CrossRef]

47. Brinker, C.J.; Frye, G.C.; Hurd, A.J.; Ashley, C.S. Fundamentals of sol-gel dip coating. Thin Solid Films 1991, 201, 97-108. [CrossRef]

48. Kuznetsov, A.V.; Xiong, M. Effect of evaporation on thin film deposition in dip coating process. Int. Commun. Heat Mass Transf. 2002, 29, 35-44. [CrossRef]

49. Buapool, S.; Thavarungkul, N.; Srisukhumbowornchai, N.; Termsuksawad, P. Modeling and Analysis of the Effect of Dip-Spin Coating Process Parameters on Coating Thickness Using Factorial Design Method. Adv. Mater. Sci. Eng. 2017, 2017, 9639306. [CrossRef]

50. Aguilar-Armenta, G.; Patiño-Iglesias, M.E.; Leyva-Ramos, R. Adsorption kinetic behaviour of pure $\mathrm{CO}_{2}, \mathrm{~N}_{2}$ and $\mathrm{CH}_{4}$ in natural clinoptilolite at different temperatures. Adsorp Sci Technol. 2003, 21, 81-91. [CrossRef]

51. Firpo, G.; Angeli, E.; Repetto, L.; Valbusa, U. Permeability thickness dependence of polydimethylsiloxane (PDMS) membranes. J. Membr. Sci. 2015, 481, 1-8. [CrossRef]

52. Selyanchyn, R.; Ariyoshi, M.; Fujikawa, S. Thickness Effect on $\mathrm{CO}_{2} / \mathrm{N}_{2}$ Separation in Double Layer Pebax-1657 ${ }^{\circledR} / \mathrm{PDMS}$ Membranes. Membranes 2018, 8, 121. [CrossRef]

53. Wijmans, J.G.; Baker, R.W. The solution-diffusion model: A review. J. Membr. Sci. 1995, 107, 1-21. [CrossRef]

54. Chong, K.C.; Lai, S.O.; Lau, W.J.; Thiam, H.S.; Ismail, A.F.; Zulhairun, A.K. Fabrication and characterization of polysulfone membranes coated with polydimethysiloxane for oxygen enrichment. Aerosol Air Qual Res. 2017, 17, 2735-2742. [CrossRef]

55. Sadrzadeh, M.; Saljoughi, E.; Shahidi, K.; Mohammadi, T. Preparation and characterization of a composite PDMS membrane on CA support. Polym. Adv. Technol. 2010, 21, 568-577. [CrossRef]

56. Roslan, R.A.; Lau, W.J.; Sakthivel, D.B.; Khademi, S.; Zulhairun, A.K.; Goh, P.S.; Ismail, A.F.; Chong, K.C.; Lai, S.O. Separation of $\mathrm{CO}_{2} / \mathrm{CH}_{4}$ and $\mathrm{O}_{2} / \mathrm{N}_{2}$ by polysulfone hollow fiber membranes: Effects of membrane support properties and surface coating materials. J. Polym. Eng. 2018, 38, 871-880. [CrossRef]

57. Wang, D.; Teo, W.K.; Li, K. Preparation and characterization of high-flux polysulfone hollow fibre gas separation membranes. J. Membr. Sci. 2002, 204, 247-256. [CrossRef]

58. Kapantaidakis, G.C.; Koops, G.H. High flux polyethersulfone-polyimide blend hollow fiber membranes for gas separation. J. Membr. Sci. 2002, 204, 153-171. [CrossRef]

59. Zulhairun, A.K.; Fachrurrazi, Z.G.; Izwanne, M.N.; Ismail, A.F. Asymmetric hollow fiber membrane coated with polydimethylsiloxane-metal organic framework hybrid layer for gas separation. Sep. Purif. Technol. 2015, 146, 85-93. [CrossRef]

60. Liu, L.; Chakma, A.; Feng, X. $\mathrm{CO}_{2} / \mathrm{N}_{2}$ separation by poly (ether block amide) thin film hollow fiber composite membranes. Ind Eng. Chem. Res. 2005, 44, 6874-6882. [CrossRef]

61. Jiang, L.; Meng, Y.; Zhang, W.; Yu, H.; Hou, X. Preparation of $\mathrm{NH}_{2}-\mathrm{SH}-\mathrm{GO} / \mathrm{SWCNTs}$ based on graphene oxide/ single-walled carbon nanotubes for $\mathrm{CO}_{2}$ and $\mathrm{N}_{2}$ separation from blast furnace gas. Microporous Mesoporous Mater. 2020, 306, 110476. [CrossRef]

62. Ma, S.; Tang, Z.; Fan, Y.; Zhao, J.; Meng, X.; Yang, N.; Zhuo, S.; Liu, S. Surfactant-modified graphene oxide membranes with tunable structure for gas separation. Carbon 2019, 152, 144-150. [CrossRef]

63. Xin, Q.; Ma, F.; Zhang, L.; Wang, S.; Li, Y.; Ye, H.; Ding, X.; Lin, L.; Zhang, Y.; Cao, X. Interface engineering of mixed matrix membrane via $\mathrm{CO}_{2}$-philic polymer brush functionalized graphene oxide nanosheets for efficient gas separation. J. Membr. Sci. 2019, 586, 23-33. [CrossRef]

64. Yang, E.; Goh, K.; Chuah, C.Y.; Wang, R.; Bae, T.-H. Asymmetric mixed-matrix membranes incorporated with nitrogen-doped graphene nanosheets for highly selective gas separation. J. Membr. Sci. 2020, 615, 118293. [CrossRef]

65. Shan, M.; Xue, Q.; Jing, N.; Ling, C.; Zhang, T.; Yan, Z.; Zheng, J. Influence of chemical functionalization on the $\mathrm{CO}_{2} / \mathrm{N}_{2}$ separation performance of porous graphene membranes. Nanoscale 2012, 4, 5477-5482. [CrossRef]

66. Widiastuti, N.; Gunawan, T.; Fansuri, H.; Salleh, W.N.W.; Ismail, A.F.; Sazali, N. P84/ZCC Hollow Fiber Mixed Matrix Membrane with PDMS Coating to Enhance Air Separation Performance. Membranes 2020, 10, 267. [CrossRef]

67. Bezerra, M.A.; Santos, Q.O.D.; Santos, A.G.; Novaes, C.G.; Ferreira, S.L.C.; de Souza, V.S. Simplex optimization: A tutorial approach and recent applications in analytical chemistry. Microchem. J. 2016, 124, 45-54. [CrossRef] 